\title{
Chapter 22 \\ Innovative Teaching and Learning \\ Climates-Is Germany Indeed Ahead of India? How Do These Relate to Sustainable Thinking?
}

\section{Luise Mayer, Elena Stasewitsch, and Simone Kauffeld}

\begin{abstract}
An innovative teaching and learning climate (ITLC) describes the positive attitudes of teachers and students towards developing and applying innovation, i.e., new ways of thinking and practices at their university. ITLC is assumed to positively affect many aspects of teaching and learning outcomes, e.g., sustainable thinking. Contrary to the hypothesis, the German university TU Braunschweig $(N=394)$ did not score higher in ITLC than BITS Pilani $(N=484)$. Sustainable thinking correlated with ITLC. This is the first study to provide insights into how ITLC relates to sustainable thinking. Thus, the results supplement existing research on sustainable thinking.
\end{abstract}

Keywords Innovative climate $\cdot$ Higher education $\cdot$ Sustainable thinking

\subsection{Introduction}

Across the world, innovating and enabling sustainable development are constantly gaining importance. As "centers of knowledge generation and sharing" (Nejati et al. 2011) universities bear the responsibility for these societal tasks (Nejati et al. 2011). Their challenge is to prepare future specialists and executives all over the world. However, even universities themselves lack innovations (Blume et al. 2015; Wals and Jickling 2002) and the ability to enable sustainable development on campus (Velazquez et al. 2005).

One speaks of innovation when a group beneficially (Nonaka 1994) applies (O'Sullivan and Dooley 2008) an idea that is new to them (Rogers, 2010). In this research, innovation includes innovative teaching and learning, and sustainable development. A high innovative climate describes an environment that is particularly conducive to innovations: Individuals share (Van der Vegt et al. 2005) positive attitudes (Alisch et al. 2013) towards new ideas and developments within their group (Van

L. Mayer (凶) $\cdot$ E. Stasewitsch · S. Kauffeld

Division of Industrial/Organizational and Social Psychology, Institute of Psychology, Technische Universität Braunschweig, Spielmannstr. 19, Braunschweig 38106, Germany

e-mail: luise.mayer@magenta.de 
der Vegt et al. 2005). Mutual appreciation and intensive communication are characteristic (Stasewitsch and Kauffeld (in press)). A high innovative climate leads to innovative behavior (Yu et al. 2013) and therefore, to innovations (Scott and Bruce 1994). This connection was found for educational institutions as well (Sagnak 2012). We use the more university-specific term innovative teaching and learning climate (ITLC) in this research.

India has the third largest higher education system in the world (Gupta and Gupta 2012). However, its reputation for education and research is relatively poor across the globe (Sharma and Sharma 2015). Probably related to this is the low employability (Sharma and Sharma 2015). Practical methods (Aymans et al. 2017; Büth et al. 2017) like internships, career counselling, and international projects (Sharma and Sharma 2015) are rarely applied in India. Whereas in Germany, innovative teaching is widespread (Kauffeld and Othmer 2019). Therefore, we propose:

- Hypothesis (H) 1.1 Didactic and technical innovations (mobile, individualized, research-orientated learning) are applied less frequently in Indian than in German universities.

- H 1.2 Indian universities have a lower innovative climate than German universities.

The comparison of an Indian university, Birla Institute of Technology and Science, Pilani, India (BITS Pilani) with an German university, Technische Universität Braunschweig (TU Braunschweig) should identify factors inhibiting innovations on BITS Pilani campus. Building on this, we aim to provide recommendations to BITS Pilani for actions to improve the ITLC. This can contribute to replacing outdated teaching and learning methods with innovative ones.

Sustainable development defines the "development that meets the needs of the present without compromising the ability of future generations to meet their own needs" (Brundtland et al. 1987, p. 37). It can be regarded as innovation even at German universities (Richter and Hunecke 2017) and as a fairly new concept in developed countries in general (Meadowcroft 2000). Consequently, sustainable thinking and acting can be understood as innovative behavior. That is why we assume that innovative climate can promote sustainable thinking. Our assumption is also supported by the fact that sustainable development at universities fails, among other things, due to a reluctance to change and poor communication (Velazquez et al. 2005). In a high ITLC, the opposite is the case; the members of the organization welcome new ideas (Scott and Bruce 1994) and have intensive relations in general (Moolenaar et al. 2011). That means ITLC tackles exactly the obstacles of sustainable development at universities.

- H 2.1 ITLC correlates positively with sustainable thinking.

At the moment, knowledge about sustainable development (Zsóka et al. 2013) and the status, i.e., the reputation of acting sustainably (Griskevicius et al. 2010) are considered to be the most important influencing factors on sustainable thinking and acting. 
- H 2.2 Knowledge about sustainable development correlates positively with sustainable thinking.

- H 2.3 The status of acting sustainably correlates positively with sustainable thinking.

This research aims to determine factors inhibiting and encouraging innovations at BITS Pilani. When purposefully increasing the ITLC, university members are more likely to generate innovations. This is shown by the innovation sustainable thinking. To classify the strength of the relation between ITLC and sustainable thinking, it is compared with that of known factors influencing sustainable thinking.

\subsection{Method}

BITS Pilani members, students and teachers took part in this research. For comparison, previously collected data (Stasewitsch and Kauffeld (in press)) from Germany (TU Braunschweig) were used. Table 22.1 shows the sample composition in terms of occupation, age, and gender.

For measuring the ITLC Inno-Teaching (or respectively, its original German version Inno-Lehre (Stasewitsch and Kauffeld (in press)) was applied. It contains twelve scales including three about didactic and technical innovations, namely Mobile, Individualized and Research-orientated Learning. Additionally, sustainable thinking (Biasutti and Frate 2017), knowledge about sustainable development (Azapagic et al. 2005), and the status of acting sustainably (Richins 1994) were measured (see Table 22.2).

Table 22.1 Sample composition

\begin{tabular}{|c|c|c|}
\hline $\begin{array}{l}\text { Sample } 1 \text { (BITS } \\
\text { Pilani) }\end{array}$ & $\begin{array}{l}\text { Sample } 2 \text { (TU } \\
\text { Braunschweig) }\end{array}$ & $\begin{array}{l}\text { Sample } 3 \text { (BITS } \\
\text { Pilani) }\end{array}$ \\
\hline $\begin{array}{l}\mathrm{n}^{\mathrm{t}}=67 \\
\varnothing=36.2(S D= \\
10.5) \\
88 \sigma^{\prime} \& 12 \% \text { ○ }\end{array}$ & $\begin{array}{l}\mathrm{n}^{\mathrm{t}}=205 \\
\varnothing=39.4(S D= \\
11.2) \\
62 \sigma^{\prime \prime} \& 32 \% \text { ᄋ }\end{array}$ & \\
\hline $\begin{array}{l}\mathrm{n}^{\mathrm{s}}=417 \\
\varnothing=20.2(S D= \\
1.9) \\
86 \sigma^{\prime \prime} \& 13 \% \text { ᄋ }\end{array}$ & $\begin{array}{l}\mathrm{n}^{\mathrm{s}}=189 \\
\varnothing=24.8(S D= \\
3.2) \\
56 \text { ơ \& } 41 \% \text { ᄋ }\end{array}$ & $\begin{array}{l}\mathrm{n}^{\mathrm{s}}=221 \\
\varnothing=20.0(S D= \\
1.8) \\
87 \text { ơ \& } 13 \% \text { ᄋ }\end{array}$ \\
\hline
\end{tabular}

Notes $\mathrm{n}=$ number of participants, $\mathrm{t}=$ teachers, $\mathrm{s}=$ students, $\varnothing$ $=$ average age, $\mathrm{SD}=$ standard deviation 
Table 22.2 Applied scales

\begin{tabular}{|c|c|c|}
\hline Measured construct & Applied scales & Subscales (number of items) \\
\hline $\begin{array}{l}\text { Innovative teaching and } \\
\text { learning climate }\end{array}$ & $\begin{array}{l}\text { Inno-Lehre and } \\
\text { Inno-Teaching (Stasewitsch } \\
\text { and Kauffeld (in press)) }\end{array}$ & $\begin{array}{l}\text { - Appreciation (3) } \\
\text { - Relationship quality (3) } \\
\text { - Networking in teaching (3) } \\
\text { - Activating leadership (3) } \\
\text { - Activating support (3) } \\
\text { - Dealing with mistakes (2) } \\
\text { - Reflection: Teachers (3) } \\
\text { - Reflection: Students (2) } \\
\text { - Aims in teaching (2) } \\
\text { - Qualification in teaching } \\
\text { (3) } \\
\text { - D. \& t. i.: Mobile learning } \\
\text { (3) } \\
\text { - D. \& t. i.: Individualized } \\
\text { learning (2) } \\
\text { - D. \& t. i.: Research } \\
\text { orientated learning (3) }\end{array}$ \\
\hline Sustainable thinking & $\begin{array}{l}\text { Attitudes towards sustainable } \\
\text { development (Biasutti and } \\
\text { Frate 2017) }\end{array}$ & $\begin{array}{l}\text { - Environment (5) } \\
\text { - Economy (5) } \\
\text { - Society (5) } \\
\text { - Education (5) }\end{array}$ \\
\hline $\begin{array}{l}\text { Knowledge about sustainable } \\
\text { development }\end{array}$ & $\begin{array}{l}\text { Knowledge about sustainable } \\
\text { development (Azapagic et al. } \\
\text { 2005) }\end{array}$ & $\begin{array}{l}\text { - Environmental issues (14) } \\
\text { - Environmental legislation, } \\
\text { policy, and standards (7) } \\
\text { - Environmental tools, } \\
\text { technologies and } \\
\text { approaches (12) } \\
\text { - Sustainable development } \\
\text { (12) }\end{array}$ \\
\hline Status of acting sustainably & $\begin{array}{l}\text { Possession rating scale } \\
\text { (Richins 1994), adapted to } \\
\text { acting sustainably instead of } \\
\text { owning possessions }\end{array}$ & (3) \\
\hline
\end{tabular}

Notes D. \& t. i. $=$ Didactic and technical innovations

\subsection{Results}

\subsubsection{Innovative Teaching and Learning Climate at BITS Pilani}

We rejected Hypotheses 1.1 and 1.2 as BITS Pilani (Sample 1) had higher values than TU Braunschweig (Sample 2) in the analyzed ITLC scales (see Table 22.3). 
Table 22.3 Comparison of ITLC between at BITS Pilani and TU Braunschweig

\begin{tabular}{l|l|l|l|l}
\hline \multirow{2}{*}{ Scale } & \multicolumn{2}{l|}{ BITS Pilani } & \multicolumn{2}{l}{ TU Braunschweig } \\
\cline { 2 - 5 } & $\mathrm{M}$ & $\mathrm{SD}$ & $\mathrm{M}$ & $\mathrm{SD}$ \\
\hline Mobile learning & 2.71 & 0.75 & 1.74 & 0.92 \\
\hline Individualized learning & 2.18 & 0.95 & 1.45 & 0.97 \\
\hline Research orientated learning & 2.63 & 0.84 & 2.14 & 0.99 \\
\hline ITLC total & 75.30 & 16.96 & 60.99 & 19.54 \\
\hline
\end{tabular}

Notes $M=$ Mean score, $S D=$ standard deviation. ITCL total is the sum of all 32 ITCL items (see Table 22.2)

\subsubsection{Sustainable Thinking and Innovative Teaching and Learning Climate}

The strength of an association can be estimated by Pearson's $r$ (Cohen and Manion 1980). According to Hypothesis 2.1 and 2.3, sustainable thinking correlated significantly to a small extent with ITLC $(r=.22, p=.00)$ and status of acting sustainably $(r=.17, p=.01)$. However, sustainable thinking did not correlate with knowledge about sustainable development $(r=-.02, p=.41)$.

\subsection{Discussion and Outlook}

\subsubsection{Innovative Teaching and Learning Climate at BITS Pilani}

Discussion. Contrary to expectations, BITS Pilani scored higher than TU Braunschweig, not only in the selected scales but also in Inno-Teaching as a whole. First of all, a problem that has occurred in the course of this research should be noted. The Hypotheses had been derived from differences between India and Germany, e.g. differences in the reputation in research and education (see 1). These were then only operationalized as BITS Pilani and TU Braunschweig, i.e., only tested at one university per country. This limits the generalizability of the results.

The high score of BITS Pilani may have two causes which are both considered in this section. Either the ITLC at the TU Braunschweig is not more pronounced compared to BITS Pilani, or the ITLC at BITS Pilani is lower than the one TU Braunschweig, but our questionnaire study was unable to capture this.

On the one hand, BITS Pilani possibly achieved a higher ITLC score in our survey despite a indeed lower ITLC than TU Braunschweig because culture influences the response behavior. In collectivist cultures (e.g., India) the group has priority instead of the individual as opposed to individualistic cultures (e.g., Germany) where the individual is in the focus (Triandis 1995). In collectivist cultures, it is crucial to make a 
good impression when in contact with strangers (Triandis 1995). Thus, Indian participants in a questionnaire study tend to respond in a socially desirable way, i.e., as they believe that they correspond to the social or cultural norm to present themselves or their group positively (Bernardi 2006). Not only culture but also different experiences influence the response behavior of individuals. The anchoring effect says individuals tend to compare things with something else that is present to them at that moment (Tversky and Kahneman 1974). Consequently, BITS Pilani members compare their experience at a private educational institution to financially worse off public educational institutions in their country. Both, social desirability and a downward comparison of the participants, might have lead to higher values regarding the ITLC of BITS Pilani.

On the other hand, the high ITLC score of BITS Pilani could result from the actual high ITLC. Perhaps the Indian education system, or at least its ITLC, is better than its reputation, or BITS Pilani sets an excellent example for Indian universities.

Similar to TU Braunschweig (www.tu-braunschweig.de/teach4tu), at BITS Pilani, a central institute provides further training for teachers and supports innovative teaching (www.bits-pilani.ac.in/tlc/Pilani/index.html). There is broad support for entrepreneurship, including financial support (www.bits-pilani.ac.in/pilani/ centerforentrepreneurial/Home), events and courses (Kumar and Jain 2015). Consequently, many alumni found start-ups (Kumar and Jain 2015). An advantage of India compared to Germany is the flexibility (Banerjee 2008). This flexibility allows the implementation of innovations and new ideas in the teaching.

Our study shows a high ITLC at an Indian university. From this result one can conclude the recommendation for German institutes to take a closer look at the "Indian way of teaching" with the aim of finding ideas, such as a greater support for entrepreneurship and enhancing flexibility.

Outlook. To what extent social desirability has indeed played a role in the comparison between BITS Pilani and TU Braunschweig can only be analyzed with further questioning by a scale interrogating social desirability. In that way, the cross-cultural comparison would more likely find out what makes one university better than another and could enable universities from different cultures to learn from each other. For the enabling of a more generalizable cross-cultural comparison in future research, it would also be helpful to record and statistically monitor the characteristics of students and universities as well as to include a private university in Germany and a public university in India. The questioning of students and teachers with experience abroad who know both universities would limit the anchoring effect and therefore increase the comparability of the results.

\subsubsection{Sustainable Thinking and Innovative Teaching and Learning Climate}

Discussion. The association between sustainable thinking and ITLC has been found for the first time. Moreover, it was the strongest correlation found compared with 
known influencing factors like knowledge about sustainable development and status of acting sustainably. Our research provides the first indications that besides teaching pure knowledge about sustainable development and presenting sustainability as cool, sustainable thinking can also be enhanced by ITLC. Thus, so far, an important factor in education for sustainable development would have been neglected.

However, as in all correlative studies, there is one significant limitation that the causal relations remain unclear. An ITLC might indeed enhance sustainable thinking. Alternatively, the two constructs could influence each other. Or, a third variable such as high social status might be associated with both the factors.

Outlook. This link should be pursued further. Longitudinal studies would be valuable to examine the cross-lagged associations between sustainable thinking and an ITLC.

Acknowledgements The research for this paper is part of the project "JInGEL_Joint Indo German Experience Lab", a joint project between Technische Universität Braunschweig and Birla Institute of Technology and Science Pilani, and is funded by the German Academic Exchange Service (DAAD) under grant number 57219215. The authors are thankful for the funding and the support. Elena Stasewitsch and Simone Kauffeld gratefully acknowledge support from the German Ministry of Education and Research under grant number 01PL17043.

\section{References}

Alisch K, Winter E, Arentzen U (2013) Gabler Wirtschafts Lexikon. Springer

Aymans S, Friese H, Kauffeld S (2017) Bildung ohne Grenzen. Intercul J: Online-Zeitschrift für interkulturelle Studien 17:61-81

Azapagic A, Perdan S, Shallcross D (2005) How much do engineering students know about sustainable development? J Eng Educ 30:1-19. https://doi.org/10.1080/03043790512331313804

Banerjee S (2008) Dimensions of Indian culture, core cultural values and marketing implications. Int J Cross Cult Manag 15(4):367-378. https://doi.org/10.1108/13527600810914157

Bernardi RA (2006) Associations between Hofstede's cultural constructs and social desirability response bias. J Bus Ethics 65:43-53. https://doi.org/10.1007/s10551-005-5353-0

Biasutti M, Frate S (2017) A validity and reliability study of the attitudes toward sustainable development scale. Environ Educ Res 23:214-230. https://doi.org/10.1080/13504622.2016. 1146660

BITS Pilani: Centre for Entrepreneurial Leadership. www.bits-pilani.ac.in/pilani/ centerforentrepreneurial/Home. Last accessed 6 June 2019

Blume S, Madanchi N, Böhme S, Posselt G, Thiede S, Herrmann C (2015) Die LernfabrikResearch-based learning for sustainable production engineering. Procedia CIRP. https://doi.org/ 10.1016/j.procir.2015.02.113

Brundtland GH, Khalid M, Agnelli S, Al-Athel S, Chidzero B (1987) Our common future. New York

BITS Pilani: Teaching and Learning Centre. www.bits-pilani.ac.in/tlc/Pilani/index.html. Last accessed 6 June 2019

Büth L, Bhakar V, Sihag N, Posselt G, Böhme S, Sangwan KS, Herrmann C (2017) Bridging the qualification gap between academia and industry in India. Procedia Manufact 9:275-282. https:// doi.org/10.1016/j.promfg.2017.04.009

Cohen L, Manion L (1980) Research methods in education, 6th edn. Croom Helm, London (1980). https://doi.org/10.4324/9780203720967 
Griskevicius V, Tybur JM, van den Bergh B (2010) Going green to be seen: status, reputation, and conspicuous conservation. J Pers Soc Psychol 98:392. https://doi.org/10.1037/a0017346

Gupta D, Gupta N (2012) Higher education in India: structure, statistics and challenges. J Edu Pract 3:17-24

Kauffeld S, Othmer J (2019) 12.1 Zielsetzung: Forschung für die Praxis-176 12.2 Forschendes Lernen in der Hochschulpraxis-176 12.3 Fazit: forschendes Lernen als studiengangprägendes Konzept-186. Handbuch Innovative Lehre 175. https://doi.org/10.1007/978-3-658-22797-5

Kumar A, Jain A (2015) Factors affecting entrepreneurial intent among students: a case study of BITS Pilani. In: 11th biennial conference on entrepreneurship. EDII, Gandhinagar (2015)

Meadowcroft J (2000) Sustainable development: a new (ish) idea for a new century? Polit Stud 48:370-387. https://doi.org/10.1111/1467-9248.00265

Moolenaar NM, Daly AJ, Sleegers PJC (2011) Ties with potential. Teach Coll Reco 113:1983-2017

Nejati M, Shafaei A, Salamzadeh Y, Daraei M (2011) Corporate social responsibility and universities. Afr J Bus Manage. https://doi.org/10.5897/AJBM2015.7993

Nonaka I (1994) A dynamic theory of organizational knowledge creation. Organ Sci 5:14-37

O’Sullivan D, Dooley L (2008) Applying innovation. Sage Publications

Richins ML (1994) Valuing things. J Consum Res. https://doi.org/10.1086/209414

Richter N, Hunecke M (2017) Die Verbreitung von Nachhaltigkeit als soziale Innovation an Hochschulen aus Sicht studentischer Nachhaltigkeitsinitiativen. In: CSR und Wirtschaftspsychologie. Springer, pp 297-308. https://doi.org/10.1007/978-3-662-52746-7_17

Sagnak M (2012) The empowering leadership and teachers innovative behavior: the mediating role of innovation climate. Afr J Bus Manage 6:1635-1641. https://doi.org/10.5897/AJBM11.2162

Scott SG, Bruce RA (1994) Determinants of innovative behavior. Acad Manag J 37:580-607. https:// doi.org/10.5465/256701

Sharma S, Sharma P (2015) Indian higher education system. Electro J Inclus Edu 3:1-4

Stasewitsch E, Kauffeld S (in press) Der Inno-Lehre: Ein Inventar zur Messung von innovativem Lehr-Lernklima an Hochschulen. Diagnostica

Stasewitsch E, Kauffeld S (in prep.) The Inno-Teaching: a cross-cultural validation

Triandis HC (1995) Individualism and collectivism. Westview Press, Bouder, CO

TU Braunschweig: teach4TU. https://www.tu-braunschweig.de/teach4tu. Last accessed 6 June 2019

Tversky A, Kahneman D (1974) Judgment under uncertainty: heuristics and biases. Science 185:1124-1131

Van der Vegt, Gerben S, van de Vliert E (2005) Huang X location-level links between diversity and innovative climate depend on national power distance. Acad Manage J 48:1171-1182. https:// doi.org/10.5465/amj.2005.19573116

Velazquez L, Munguia N, Sanchez M (2005) Deterring sustainability in higher education institutions. Int J Sus in Higher Ed 6:383-391. https://doi.org/10.1108/14676370510623865

Wals AEJ, Jickling B (2002) "Sustainability" in higher education. Int J Sus in Higher Ed. https:// doi.org/10.1108/14676370210434688

Yu C, Yu T-F, Yu C-C (2013) Knowledge sharing, organizational climate, and innovative behavior: a cross-level analysis of effects. Soc Behav Personal Int J 41:143-156. https://doi.org/10.2224/ sbp.2013.41.1.143

Zsóka Á, Szerényi ZM, Széchy A, Kocsis T (2013) Greening due to environmental education? J Clean Prod 48:126-138. https://doi.org/10.1016/j.jclepro.2012.11.030 
Open Access This chapter is licensed under the terms of the Creative Commons Attribution 4.0 International License (http://creativecommons.org/licenses/by/4.0/), which permits use, sharing, adaptation, distribution and reproduction in any medium or format, as long as you give appropriate credit to the original author(s) and the source, provide a link to the Creative Commons license and indicate if changes were made.

The images or other third party material in this chapter are included in the chapter's Creative Commons license, unless indicated otherwise in a credit line to the material. If material is not included in the chapter's Creative Commons license and your intended use is not permitted by statutory regulation or exceeds the permitted use, you will need to obtain permission directly from the copyright holder.

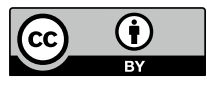

